\title{
Management of fracture of neck talus and clinical evaluation of results
}

\author{
Satish R. Gawali ${ }^{1 *}$, Gajanan Kathar ${ }^{2}$, Pramod V. Niravane ${ }^{3}$, Mansoor Bhosage ${ }^{4}$
}

\author{
${ }^{1}$ Associate Professor, Department of Orthopedics, Government Medical College and Hospital, Latur, Maharashtra, \\ India \\ ${ }^{2}$ Senior Resident, Department of Orthopedics, Government Medical College and Hospital, Latur, Maharashtra, India \\ ${ }^{3}$ Junior Resident III, Department of Orthopedics, Government Medical College and Hospital, Latur, Maharashtra, India \\ ${ }^{4}$ Senior Resident, Department of Orthopedics, Government Medical College and Hospital, Latur, Maharashtra, India
}

Received: 24 June 2016

Revised: 28 June 2016

Accepted: 01 July 2016

\author{
*Correspondence: \\ Dr. Satish R. Gawali, \\ E-mail: satishgawali61@gmail.com
}

Copyright: $($ ) the author(s), publisher and licensee Medip Academy. This is an open-access article distributed under the terms of the Creative Commons Attribution Non-Commercial License, which permits unrestricted non-commercial use, distribution, and reproduction in any medium, provided the original work is properly cited.

\begin{abstract}
Background: Fracture of neck of talus is rare and serious injury with significant complication rate. The talus is involved in about $2 \%$ of all lower extremity injuries and about 5-7\% of foot injuries. Talus neck fixation is associated with serious complications such as stiffness at ankle and subtler joint, AVN of body of talus, ankle arthritis and later on subtalar arthritis. The objective was to study and evaluate the operative treatment for talus neck fracture.

Methods: All adult patients with talus neck fracture admitted in government medical college and hospital, Latur, Maharashtra, India from January 2006 to December 2015 were involved. There were 15 patients with 10 males and 05 females. Fractures were classified as per Hawkins classification and were treated with closed/open reduction and internal fixation with CC screws.

Results: All patients were followed prospectively post operatively and clinical and radiological evaluation was done. Results were analyzed. We noted skin complications in 02 patients and rate of consolidation was 60-70\%. The final follow-up examination included determination of the AHS score (ankle-hind foot scale) from the American orthopaedic foot and ankle society (AOFAS), range of motion evaluation and radiological analysis.

Conclusions: Displaced talar neck fractures are a therapeutic challenge which has significant early and late complications. Despite of all excellent management, non-union rate in type III, and type IV Hawkins fracture is $85 \%$; and AVN of body of talus is $90-95 \%$ due to inherent complications of cut off of blood supply which comes from talar neck. Types II, III, IV were associated with talar body dislocation which caused excessive pressure on soft tissues having significant soft tissue complications. Early anatomical reduction and stable fixation is of vital importance to achieve successful outcome.
\end{abstract}

Keywords: Talus fracture, Hawkins classification, Hawkins sign, Post-traumatic arthritis, Talus neck

\section{INTRODUCTION}

Only $2 \%$ of all lower extremity injuries and $5 \%-7 \%$ of foot injuries involve fracture of talus. ${ }^{1}$ Talus is second most commonly fractured tarsal bone after calcaneus. ${ }^{2}$ Fracture and dislocations of talus are infrequently encountered injuries; but are challenging injuries. So also, scarce evidence is available in the literature on these fractures and its management. Overall talus neck fracture account for $50 \%$ of these injuries. Many controversies surround the treatment of talus neck fracture which reflects the difficulty of assessment, surgical approach, fixation method and frequency of post-op complications. ${ }^{2}$ 
Management of fracture talus depends entirely upon whether or not fracture is displaced and so thorough assessment is essential in its management. Also, talus is unique in having no muscular attachment; $60 \%$ of its surface is covered by articular cartilage and is an integral component of the ankle joint and has been well known for its precarious blood supply. Outcome may be poor with disability due to non-union, development of avascular necrosis and osteoarthritis. ${ }^{3}$ Talus neck fracture are commonly the result of hyper-dorsiflexion injuries and are often secondary to high energy trauma, often associated with other injuries and commonly present with foot and ankle swelling and deformity. ${ }^{6}$

Anderson et al described the "Aviators astralagus" which were talar neck fractures commonly seen in pilots during the World War 1 as a result of hyper dorsiflexion injury at the time of landing. Coltart et al, reviewed 25,000 fracture sustained during World War II and found 228 talar fractures, 106 were classified as talar neck. They reported osteonecrosis rate of $35 \%$ with subtalar dislocation and $95 \%$ with ankle and subtalar dislocation. ${ }^{5}$

The appropriate diagnosis and treatment of these fractures play an important role in the patient's outcome. Treatment has evolved slowly throughout the years, from closed treatment to open reduction and internal fixation (ORIF). ${ }^{11}$ The treatment of type I and type II talar neck fractures is not uniform in the orthopedic community.

The option of closed reduction versus ORIF is dependent upon the degree of injury, surgeon experience, and preference..$^{9,10}$ The frequent incidence of serious complications of skin dehiscence, non-union, osteonecrosis, neurovascular injuries, pain, stiffness and post traumatic arthritis of the subtalar and the ankle joint, leads to high risk of unsatisfactory results. Still, the talus fracture remain among the most interesting and difficult injuries in orthopaedic trauma. ${ }^{1}$

This article present a prospective study of talus neck fracture, their management and their rehabilitation in tertiary care institute.

\section{METHODS}

This is a prospective study initiated in January 2006 to December 2015 at Government Medical College and Hospital, Latur, Maharashtra. All adults patients with talus fracture of any etiology after consent for the study were included in the study. Patients were managed surgically. Surgical management includes closed/open reduction and internal fixation with $\mathrm{K}$-wire or cannulated cancellous screw $(4.0 \mathrm{~mm})$.

\section{Inclusion criteria}

All adult patients with talus fracture, admitted in GMC and Hospital, Latur, Maharashtra, India were included in the study. Informed consent obtained from all participants.

\section{Exclusion criteria}

Associated neuro-vascular injuries, neuropathic joints.

\section{Methodology}

- All patients with ankle and foot injuries with axial loading were assessed for talus fracture.

- Thorough clinical examination is done to rule out associated soft tissue and foot injuries.

- Radiographic evaluation with Antero-posterior, Lateral, and oblique radiographs of the foot and Antero-posterior view of the ankle were obtained.

- Fractures were studied with characters like, type, displacement, comminution, and incongruity of subtalar, ankle and /or talo-navicular joints.

\section{Classification}

Hawkins's classification is mostly used to classify talar fractures, it is simple and provides guidelines for the treatment and predicts the prognosis. Hawkins's classified talar fractures into: Type I, II, III and IV.

- Type I: Fracture without associated joint dislocation i.e. un-displaced fracture of talar neck.

- Type II: Talar neck fracture with associated subluxation or dislocation of the subtalar joint.

- Type III: Fracture neck talus with dislocation of the ankle as well as of subtalar joint.

- Type IV: Type III with associated subluxation/dislocation of the talo-navicular joint.

According to above classification system fractures were classified and treatment option selected and decision was taken.

In Hawkins type II fracture with subluxation and dislocation of talus an attempt of closed reduction done with distraction and planter-flexion.

The operation in this study was done with anterolateral approach with additional exposure if necessary, with antero-medial incision and posterior lateral approach.

In cases with associated medial malleolus fracture the antero-medial incision is taken which includes medial malleolus.

In antero-medial approach is made from anterior aspect of medial malleolus to the dorsal aspect of navicular tuberosity. Disruption of deltoid ligament should be avoided as it will further violate remaining blood supply to the body of talus. 
If required the antero-lateral hind foot approach is made to confirm accuracy of reduction and also facilitate the removal of fracture debris/osteo-chondral fragments from the subtalar joint.

Fracture comminution is frequently present on the medial aspect of neck of talus and visualizing lateral aspect of the neck can provide a more accurate gauge of adequacy of reduction (comminution on lateral aspect is rare).

In the study, it was tried to avoid varus mal-reduction of the neck of talus, in cases of comminution of neck of talus by direct visualization and it is also found that fracture site has diastasis or gap of the fracture if malpositioned in varus.

After provisional reduction it was stabilized with $02 \mathrm{~K}$ wires from posterior body to anteriorly head of talus engaging subchondral bone. Alignment of neck is inspected with intra-operative anterio-posterior foot, lateral foot, canale view (150 internal rotations and tilting of C-arm 750 cephalic direction-modified anteroposterior view)

After confirming quality of reduction, fracture is fixed with $4.0 \mathrm{~mm}$ Screws CC et al, as definitive fixation, 01 K-wire and 01 Screws OR 02 Screws were used across fracture site. Care is taken that screw heads must be buried deep to cartilage so as to avoid impingement. (Figure 1-6).

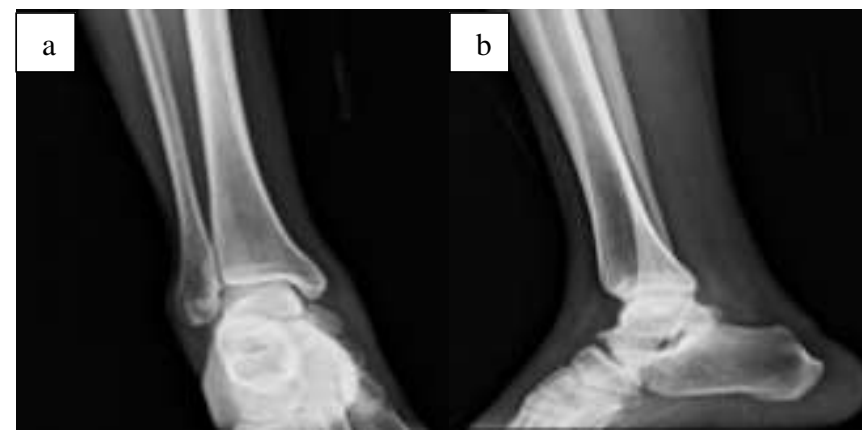

Figure 1: Type 1 Hawkins pre-operative a) AP view; b) lateral view.
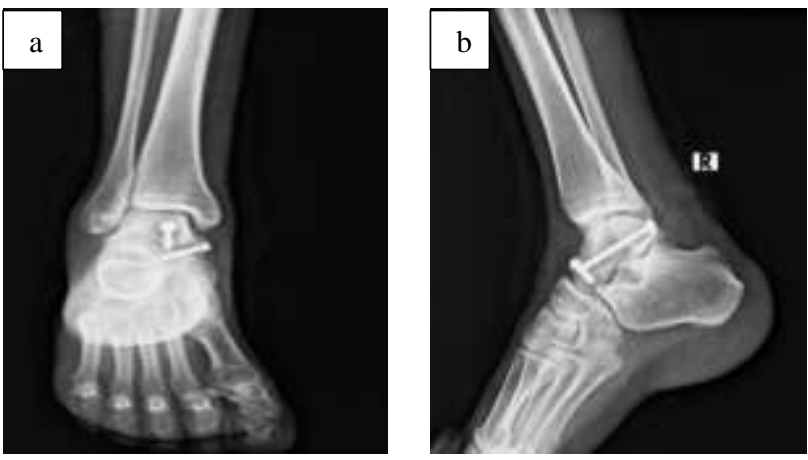

Figure 2: Type 1 Hawkins post-operative a) AP view; b) lateral view.
In Hawkins type III and type IV fracture dislocation Denham's pin passed in calcaneus to do distraction at ankle and subtalar joint. If dislocation is postero-medial with intact medial malleolus which causes obstruction to reduction of rotated talar body, osteotomy of medial malleolus was done. Steinmann pin is passed in nonarticular surface of talus to have good control over talar body fragment which helps in doing reduction and used as joystick. Generally such types of fracture dislocation were associated with spiral fracture of fibula which has fixed to give stable ankle mortise.
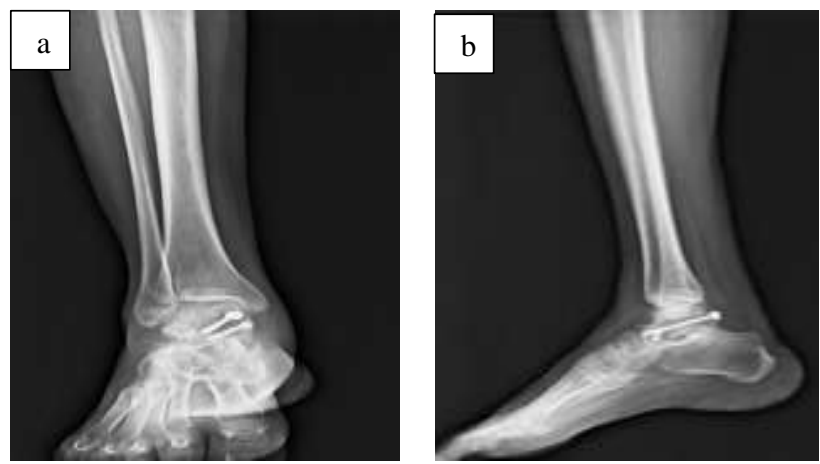

Figure 3: Type 1 Hawkins; at 14 weeks with consolidation of fracture; a) AP view, b) lateral view.
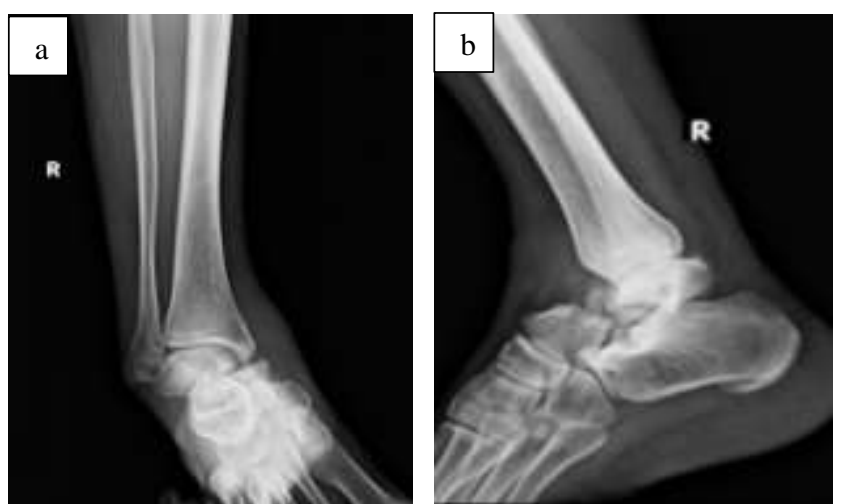

Figure 4: Type 2 Hawkins pre-op a) AP view; b) lateral view.
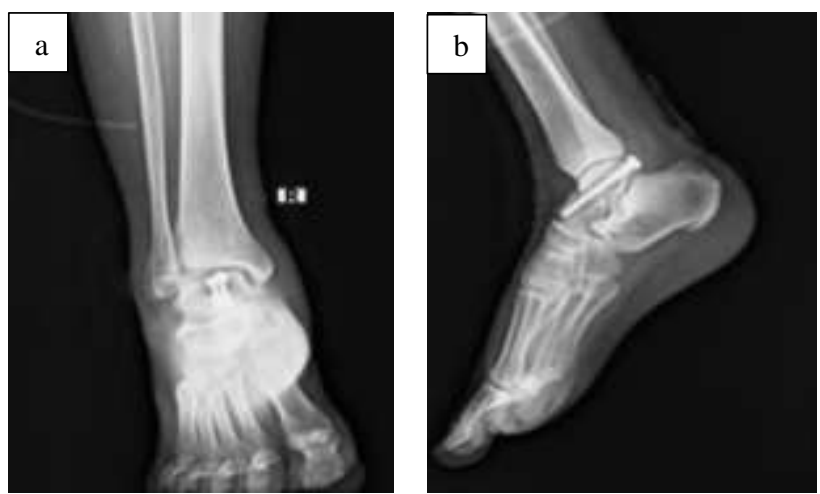

Figure 5: Type 2 Hawkins post-operative a) AP view; b) lateral view. 


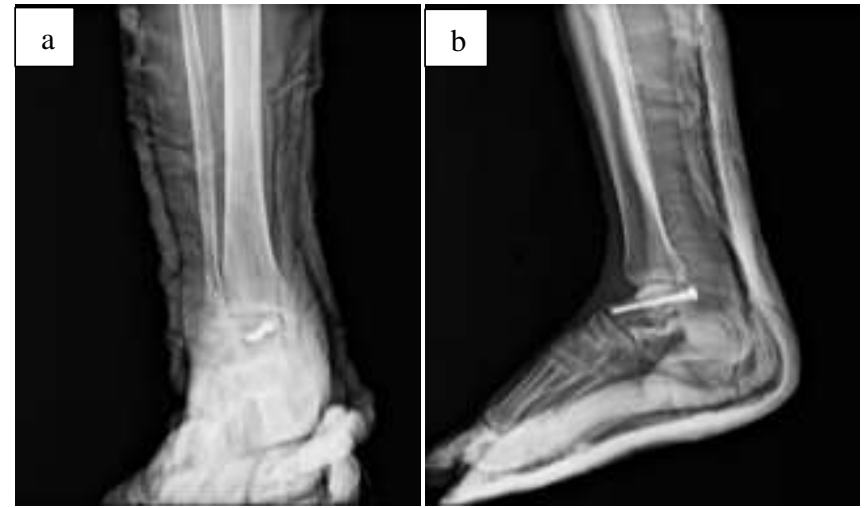

Figure 6: Type 2 Hawkins follow up 12 weeks with union. a) AP view; b) lateral view.

In cases with malleolus fracture and in Hawking type 3 and 4, additional stabilization with Delta frame external fixator is applied with foot on neutral position. This lead to early soft tissue healing and improved stability of construct. So also it reinforces the internal fixation construct with K-wires and screws.In other cases posterior POP slab with ankle in neutral position is applied (Figure 7-11).
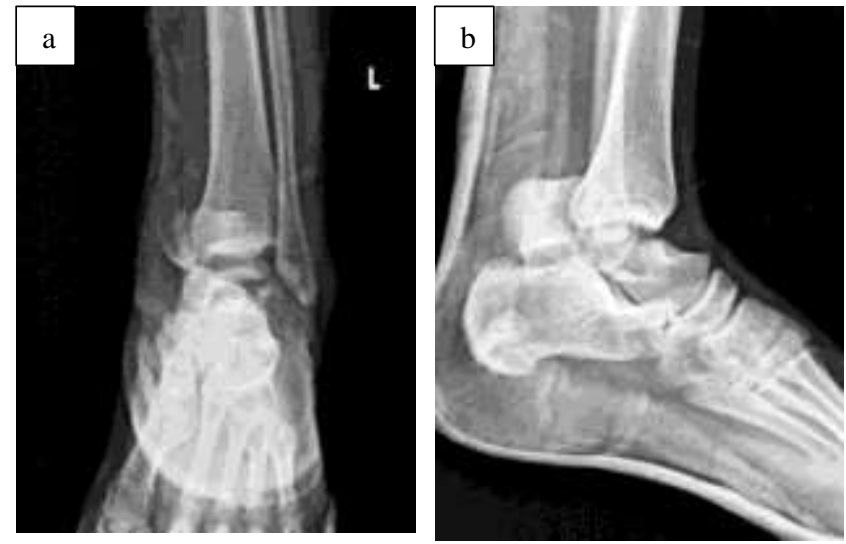

Figure 7: Type 3 Hawkins pre-operative a) AP view; b) lateral view.

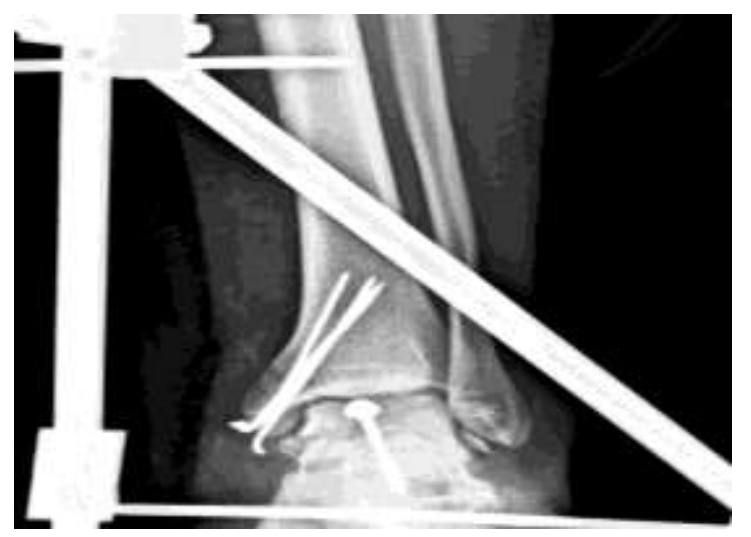

Figure 8: Type 3 Hawkins post-operative.
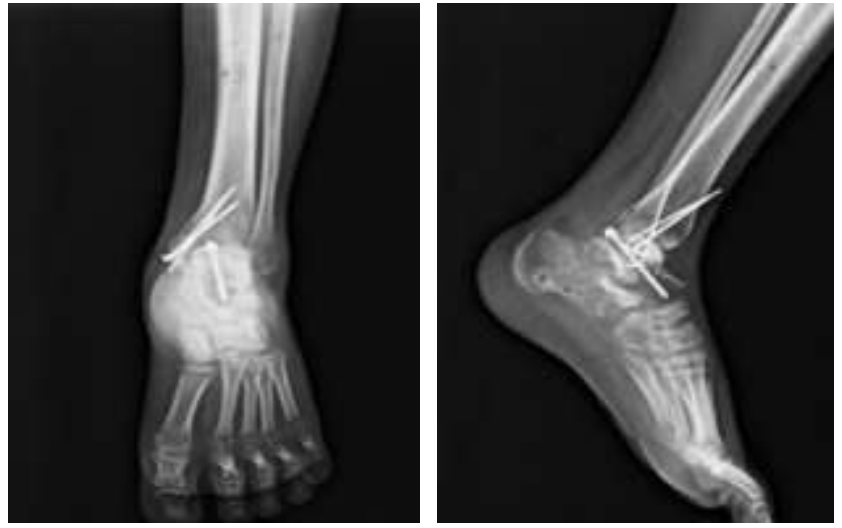

Figure 9: Type 3 Hawkins; follow up AP 14 weeks.
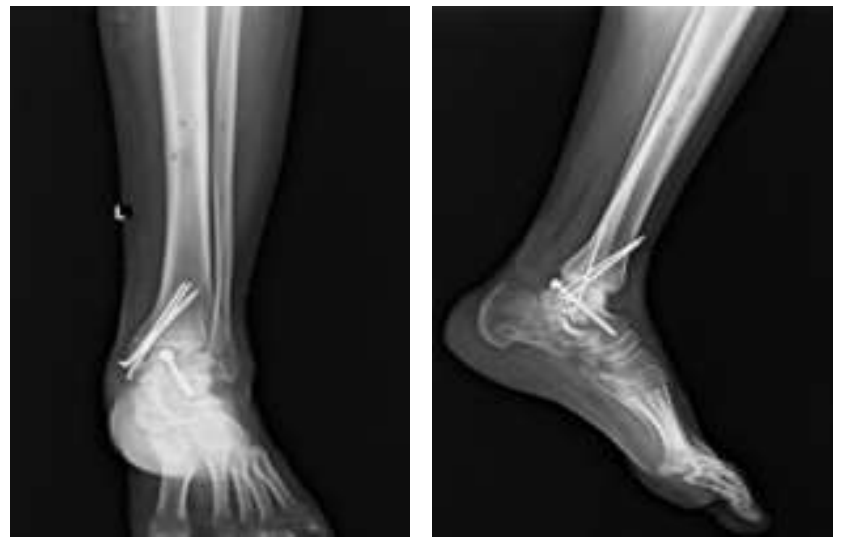

Figure 10: Type 3 Hawkins; follow up-UNION at 6 months.

Incision is closed in layers with Vicryl 2-0, and skin closed with Ethilon 2-0 sutures. Sterile dressing applied and intravenous third generation Cephalosporines or broad spectrum antibiotics were given for 07 days. Antioedema measures such as strict limb elevation, tab. serratiopeptidase or trypsin/chymotrypsin with bromelain is given for 10 days. Post op check dressing were done at 2nd day and 7 the day. Sutures were removed on 10/12th post-operative days. Patients were followed up at 4 weeks, 10 weeks, 14 weeks and 6 months, 12 months and 24 months.

In cases with delta frame external fixator, was removed at 4 weeks of follow up. Ankle and subtalar range of motion exercises was started. Care was takes to avoid strict non weight bearing for 10-14 weeks after surgery. By this time radiological signs of union are seen.

Clinical evaluation of soft tissue healing, skin necrosis, superficial infection was done at follow up (Table 1). Radiological evaluation was conducted to detect any signs of AVN, osteoarthritis of subtalar and ankle joint, nonunion, malunion at every follow up (Figure 11).

A sign of osteonecrosis like Hawkins sign is examined in $\mathrm{AP}$ and lateral radiographs in follow up. 


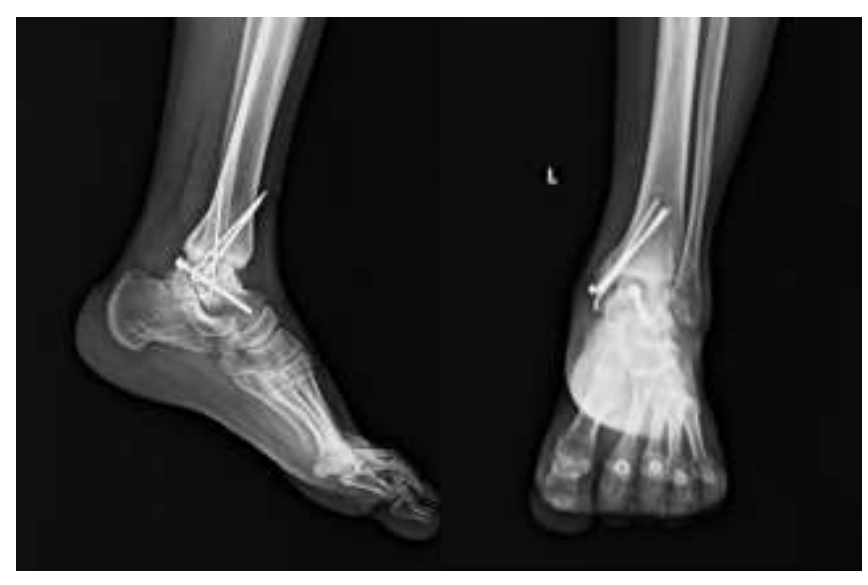

Figure 11: Follow up 18 months-AVN of body of talus and early ankle arthritis a) lateral view; b) AP view: AVN of body of talus.

Final outcome was assessed with AHS score (ankle-hind foot scale) from the American orthopaedic foot and ankle society (AOFAS), range of motion evaluation and radiological analysis.

\section{RESULTS}

Most fractures were due to road traffic accidents as seen in $8(53.34 \%)$ cases, followed by fall from height in $4(26.67 \%)$ cases and sports injury in $3(20.00 \%)$ patients. Out of the 15 fractures, 12 presented within 24 hours of injury and 03 presented after 24 hours after injury to the hospital. Out of the 15 talar neck fractures, 13 were operated with screw fixation and $\mathrm{K}$ wires, 01 were fixed with cross $\mathrm{K}$ wires and 1 patient with type 1 Hawkins treated conservatively with POP cast as pt was not fit for surgery.

Skin necrosis and wound dehiscence was commonly seen in type 3 and type 4 Hawkins fracture (Table 1).

Table 1: Early complication.

\begin{tabular}{|llll|}
\hline $\begin{array}{l}\text { Hawkins } \\
\text { type/complication }\end{array}$ & $\begin{array}{l}\text { Number } \\
\text { of cases }\end{array}$ & $\begin{array}{l}\text { Skin } \\
\text { necrosis }\end{array}$ & $\begin{array}{l}\text { Wound } \\
\text { dehiscence }\end{array}$ \\
\hline I & 4 & 00 & 01 \\
\hline II & 4 & 01 & 00 \\
\hline III & 5 & 01 & 02 \\
\hline IV & 2 & 01 & 01 \\
\hline Total & 15 & 03 & 04 \\
\hline
\end{tabular}

Secondary ankle arthritis and subtalar arthritis was developed around 7-9 months post fracture. Ankle arthritis developed in 02 cases of type 2 hawkins, 04 cases of type 3 hawkins and 02 cases of type 4 hawkins (Table 2). Avascular necrosis was seen in type 2 hawkins with 03 cases, type 3 hawkins with 04 cases and type 4 hawkins with 02 cases (Table 2). Nonunion was seen in 06 cases, 10 months post fracture and were seen in cases where conservative measures/operative treatment was employed (Table 2).
Table 2: Outcome of operative treatment.

\begin{tabular}{|llllll|}
\hline $\begin{array}{l}\text { Hawkins } \\
\text { type }\end{array}$ & $\begin{array}{c}\text { Number } \\
\text { of } \\
\text { cases }\end{array}$ & AVN & $\begin{array}{l}\text { Complications } \\
\text { Non- } \\
\text { union }\end{array}$ & $\begin{array}{l}\text { Ankle } \\
\text { arthritis }\end{array}$ & $\begin{array}{l}\text { Subtalar } \\
\text { arthritis }\end{array}$ \\
\hline I & 4 & 00 & 00 & 00 & 00 \\
\hline II & 4 & 03 & 01 & 02 & 00 \\
\hline III & 5 & 04 & 03 & 04 & 03 \\
\hline IV & 2 & 02 & 02 & 02 & 02 \\
\hline Total & 15 & 09 & 06 & 08 & 05 \\
\hline
\end{tabular}

Secondary subtalar arthritis was seen 05 patients (33.34\%). Type 3 hawkins with 03 cases and type 4 hawkins with 02 cases.

The study had a 03 year follow up in $90 \%$ patients, at the end of 1 year, $60 \%$ patients had a good and $30 \%$ patients had a fair prognosis.

\section{DISCUSSION}

Management of talar neck fractures should be focused for prevention of impending complications. Mainstay of treatment is early anatomical reduction and stable within 6-8 hours and Internal fixation which minimises complications. ${ }^{10,11}$

The common reason for postponing surgery is significant soft tissue oedema or delayed presentation after injury. Lindevall et al, in study of 26 fractures found that, time to surgical fixation should be minimized and development of AVN does not depend on delay of surgery. ${ }^{11}$

Limitations for this study was small sample size, still results of other study such as studies by Hawkins et al and Low et al, has been considered in this study that AVN was difficult to identify on plain X-rays, osteophytes and subchondral cyst are late signs of posttraumatic arthritis or AVN.

For ORIF, antero-medial approach was more versatile. ${ }^{9,15}$ Patients with significant soft tissue injury had less satisfactory results. Type I and II have better union rate and less AVN percentage as compared to type III and type IV.

Early anatomical reduction (within 6-8 hours of injury) and stable internal fixation is of vital importance to achieve successful outcome.

\section{CONCLUSION}

Displaced talar neck fractures are a therapeutic challenge which has significant early and late complications.

Despite of all excellent management, non-union rate in Type III, and type IV Hawkins fracture is $85 \%$. And AVN of body of talus is $90-95 \%$ due to inherent complications of cut off of blood supply which comes 
from talar neck. Types II, III, IV were associated with talar body dislocation which caused excessive pressure on soft tissues. So they were associated with significant skin complications. Early anatomical reduction (within 6-8 hours of injury) and stable internal fixation is of vital importance to achieve successful outcome.

\section{ACKNOWLEDGEMENTS}

The authors are very grateful to all patients who consented for this study without which our efforts were futile. The study is sincere attempt to treat the patients with minimal invasive methodology and desire to get excellent functional outcome in tertiary care hospital, following strict orthopedic principles. They also like to acknowledge all para-clinical staff, concerned human efforts towards patient care in this endeavor.

Funding: No funding sources Conflict of interest: None declared

Ethical approval: The study was approved by the institutional ethics committee

\section{REFERENCES}

1. Sanders DW. Fracture and dislocations of talus. In Rockwood and Greens Fracture in adults. $8^{\text {th }}$ edition. Wolters Kluwer Health;2015:2593-4.

2. Canale ST, Beaty JH, Campbell operative orthopaedics. Edn International. 2012;4(12):4162-3.

3. Eastwood DM. Foot Decision Making. AO Principles of fracture management. $4^{\text {th }}$ edition. Thieme Stuttgart: New York;2000:591.

4. Anderson HG. The medical and surgical aspects of aviation. London: Oxford University Press; 1919:49.

5. Charcot JM. Sur Quelques Arthropathies qui paraissentpendred'une lesion cerveauou de la moelleepiniere. Arch Physiol Normale Pathol. 1868;1:161-78.
6. Juliano PJ, Dabbah M, Harris TG. Talar neck fractures. Foot Ankle Clin. 2004;9(4);723-36.

7. Dormans JP, Fischer RC, Pill SG. Orthopaedics in the developing world: present and future concerns. J Am Acad Ortho Surg. 2001;9:289-96.

8. Kitaoka HB, Alexander IJ, Adelaar RS, Nunley JA, Myerson MS, Sanders M. Clinical rating system for the ankle, hindfoot, midfoot, hallux and lesser toes. Foot Ankle Int. 1994;15:349-53.

9. Grob D, Simpson LA, Weber BG, Bray T. Operative treatment of displaced talar neck fractures. Clin Orthop. 1985;199:88-96.

10. Comfort TH, Behrans F, Gaither DW, Denis F, Sigmond M. Long-term results of displaced talar neck fractures. Clin Orthop. 1985;199:81-7.

11. Lindvall E, Haidukewych F, Dipasquale $T$, Herscovici D, Sanders R. Open reduction and stable fixation of isolated, displaced talar neck and body fractures. J Bone Joint Surg. 2004;86:2229-34.

12. Garcia RE, Sanz HFJ, Galdran FJ, Cano EJM, Alcazar LFL. Talar neck fractures: results and complication by type. J Foot Ankle Surg. 2002;8:203-8.

13. Schulze W, Richter J, Russe O, Ingelfinger P, Muhr G. Surgical treatment of talus fractures: A retrospective study of 80 cases followed for 1-15 years. Acta Orthop Scand. 2002;73:344-51.

14. Saudan M, Peter R, Delmi M. Talar neck fractures. A 9-year follow-up of 40 cases. Rev Chir Orthop Reparatrice Appar Mot. 2002;88:168-76.

15. Onuminya JE. The role of the traditional bonesetter in primary fracture care in Nigeria. S Afr Med J. 2004;94:652-8.

Cite this article as: Gawali SR, Kathar G, Niravane PV, Bhosage M. Management of fracture of neck talus and clinical evaluation of results. Int J Res Orthop 2016;2:80-5. 